\title{
BMJ Open Patients' experiences of medicines on initiation of antineoplastic agents for the treatment of colorectal cancer: a qualitative study
}

\author{
Alison Brincat (D , ${ }^{1}$ Patricia Vella Bonanno, ${ }^{2}$ Derek Stewart, ${ }^{3}$ Anita E Weidmann ${ }^{4}$
}

To cite: Brincat A, Vella Bonanno P, Stewart D, et al. Patients' experiences of medicines on initiation of antineoplastic agents for the treatment of colorectal cancer: a qualitative study. BMJ Open 2021;11:e047749. doi:10.1136/ bmjopen-2020-047749

- Prepublication history and additional supplemental material for this paper are available online. To view these files, please visit the journal online (http://dx.doi.org/10.1136/ bmjopen-2020-047749).

Received 07 December 2020 Accepted 08 December 2021

Check for updates

(C) Author(s) (or their employer(s)) 2021. Re-use permitted under CC BY-NC. No commercial re-use. See rights and permissions. Published by BMJ.

${ }^{1}$ School of Pharmacy and Life Sciences, Robert Gordon University, Aberdeen, UK 2Department of Health Systems Management and Leadership, University of Malta, Msida, Malta ${ }^{3}$ Department of Clinical Pharmacy and Practice, Qatar University, Doha, Qatar

${ }^{4}$ Department of Clinical Pharmacy, University of Innsbruck, Innsbruck, Austria

Correspondence to

Ms Alison Brincat;

a.brincat@rgu.ac.uk

\section{ABSTRACT}

Objective To explore the patients' experiences on initiation of treatment with antineoplastic medicines for colorectal cancer.

Design A qualitative study using semistructured, face-to-face interviews based on the adapted patients' lived experience with medicines conceptual model was conducted. Ethics approval was granted. Interviews took place while eligible patients were receiving their first cycle of antineoplastic medicines, audiorecorded and transcribed verbatim. Interpretative phenomenological analysis was used.

Setting National oncology hospital in Malta. Participants Adult patients over 18 years, newly diagnosed with colorectal cancer and initiating treatment with 5-fluorouracil/folinic acid and oxaliplatin (FOLFOX) or capecitabine plus oxaliplatin (XELOX) between October 2018 and September 2019 were recruited. Patients were included if fully aware of their diagnosis and the treatment being received. A purposive sample of 16 patients participated in the study.

Results Five themes emerged from our analysis: (1) beliefs and knowledge on cancer and treatment; (2) healthcare system in relation to treatment; (3) medicinetaking practice; (4) medicine-related impact and (5) personal support structure. In addition, 16 subthemes were identified to describe the interplay of all aspects of the patients' experiences on initiation of treatment with antineoplastic medicines.

Conclusion This qualitative study illustrated that the patients find themselves in a complex situation on initiation of treatment with antineoplastic medicines. The patients' knowledge on their specific treatment and active participation in making an informed decision need to be addressed. The healthcare system should develop tailored patient-centred services that specifically address the lack of patient empowerment and patient's concern about treatment specific information.

\section{INTRODUCTION}

Colorectal cancer (CRC) is a major public health concern, being the third most commonly diagnosed cancer affecting about 1.8 million individuals annually worldwide. It is the second-leading cause of cancer-related
Strengths and limitations of this study

To our knowledge, this is the first qualitative study to explore the patients' experience on initiation of treatment with antineoplastic medicines for colorectal cancer

- The interpretative phenomenological design was used to explore the patients' complex experiences, beliefs and behaviours with antineoplastic medicines.

- The study findings can be used to inform delivery of individualised care and support provided to patients with colorectal cancer.

- Although data saturation was achieved, the qualitative approach prohibits generalisation; results should be interpreted with caution with regards to transferability to other patient groups and settings.

mortality globally with around 900000 annual deaths. ${ }^{1-3}$

The European Society for Medical Oncology Clinical Practice Guidelines recommend that the treatment choice for localised CRC is primarily surgery, combined with adjuvant antineoplastic medicines depending on the risk of recurrence. ${ }^{4}$ In case of metastatic $\mathrm{CRC}$, antineoplastic medicines in combination with targeted agents are indicated as firstline treatment with palliative intent. ${ }^{5}{ }^{6}$ For more than 40 years, the baseline treatment of CRC has been 5 -fluorouracil, with oxaliplatin introduced later in the treatment protocol (FOLFOX). More recently oral capecitabine has been introduced to be considered as an alternative to the 5-fluorouracil infusion (XELOX). ${ }^{7-9}$ Despite dramatic improvements in median survival time (from 10 months to $>24$ months) through the use of adjuvant antineoplastic medicines, quality of life (QOL) still varies dramatically among patients with CRC. ${ }^{8-11}$

Patient-reported outcome measures and experience measures have been commonly 
used as key instruments to assess quality in healthcare and improvement in QOL. ${ }^{12}$ Studies published during the last decade reported that patients with CRC tend to have lower health-related QOL, with impact on daily functioning due to psychosocial effects. The rise in the number of patients living with the consequences of a CRC diagnosis and the different treatment modalities have led to a greater interest in the patients' expectations in the context of medical treatment and the health-related QOL. ${ }^{13-15}$

The patients' lived experience with medicines (PLEM) is a complex phenomenon highlighted in the systematic review by Mohammed et al. ${ }^{16}$ This exposed the patient's reality of living with medicines for acute and chronic conditions, the burden on their daily life and the impact from beliefs, behaviours, health and well-being. The resultant conceptual model of PLEM incorporated three major inter-related themes: medicine-related burden, medicine-related beliefs and medicine-taking practice. ${ }^{16}$ A later systematic review by Brincat et $a l^{17}$ focused on these three themes in relation to the use of antineoplastic medicines in the management of malignant solid cancers. Ten studies collectively provided an account on beliefs, practice and burden of oncology patients receiving different antineoplastic medicines at varying time points during their treatment journey. Aside from disclosing that oncology patients considered treatment with antineoplastic medicines either as 'hope or worse than the illness itself', ${ }^{17}$ the review highlighted that their use also has a profound effect on the patients' daily life. An adaptation of the original model of PLEM was proposed to reflect the specific needs of oncology patients. A paucity of literature in exploring medicine related burden, beliefs and practice following initiation of antineoplastic medicines was also noted. ${ }^{17}$ Hence, this study aimed to explore the patients' experiences on initiation of treatment with antineoplastic medicines for CRC.

\section{METHOD}

The study is reported in accordance with the Standards for Reporting Qualitative Research guidelines ${ }^{18}$ (online supplemental file). Trustworthiness was assured by consideration of the concepts of credibility, dependability, transferability and confirmability postulated by Lincoln and Guba. $^{19}$

\section{Study design}

The study adopted a qualitative study design using interpretative phenomenological analysis (IPA) to gain understanding of the subjective meaning of initiation of treatment with antineoplastic medicines. This idiographic approach allows in depth analysis of experiences of small groups of participants in particular setting. ${ }^{20} 21$

\section{Reflexivity}

All members of the research team (AB, PVB, DS and AEW) are pharmacists with extensive knowledge in the field of clinical pharmacy. A team member (DS) is a recognised expert in qualitative research and the other two (AB and PVB) have experience as hospital pharmacists in oncology setting. Their clinical experience may optimise the research process (eg, identification of ideal time to conduct interviews with patients in the hospital setting).

\section{Study setting}

The study took place at Sir Anthony Mamo Oncology Centre, the only oncology hospital within the public health system in Malta with 113 beds catering for almost 1400 new cases annually. ${ }^{22}$

\section{Participant selection}

Patients were eligible if aged $\geq 18$ years diagnosed with $\mathrm{CRC}$ and first-time receiving either FOLFOX or XELOX as part of 12 or 8 cycles, respectively. They had to be fully aware of their diagnosis and treatment. Patients were excluded in case of a history of antineoplastic treatment or inability to communicate in English or Maltese. Patients were recruited using purposive sampling to include a diverse range of demographic characteristics and with different treatment intents (curative or palliative). Sample size was determined on the basis of data saturation, according to the process of Francis $e t a l,{ }^{23}$ with an initial sample of 12 patients. Further patients were recruited until new participants were not adding any additional insights.

\section{Development of interview guide}

A semistructured interview guide (table 1), underpinned by the conceptual PLEM model adapted for the oncology setting in the systematic review by Brincat $e t a l,{ }^{17}$ was developed in both Maltese and English. The draft interview guide was submitted to a panel of three healthcare research experts for critical review. A pilot study was conducted on a sample of four patients recruited under identical conditions to the main study. Any changes to the interview guide were documented to enhance dependability. As no major changes to the interview guide were necessary following the pilot study, the data generated was incorporated into the analysis of the actual study.

\section{Data generation}

In-depth one-to-one semistructured interviews were conducted with patients on the first or second day of their first treatment cycle with parenteral antineoplastic medicines. These were conducted between October 2018 and September 2019 by the same member of the research team who received training in qualitative interviewing $(\mathrm{AB})$. Participants were offered a single person interview as the first line option and allowed the presence of a second person if this was requested by the patient. Interviews lasted approximately 40 minutes, digitally audiorecorded and transcribed verbatim. Data were anonymised using a unique participant reference code. A 10\% sample of transcripts were randomly selected and cross-checked by a person independent to the study to ensure reliability of transcribing. 


\begin{tabular}{|c|c|c|}
\hline $\begin{array}{l}\text { PLEM major themes from } \\
\text { original model }^{16}\end{array}$ & $\begin{array}{l}\text { PLEM themes from the adapted } \\
\text { model }^{17 \star}\end{array}$ & Interview questions \\
\hline \multirow[t]{3}{*}{ Medicine related beliefs } & $\begin{array}{l}\text { Family members, healthcare } \\
\text { professionals, media and culture } \\
\text { influence }\end{array}$ & $\begin{array}{l}\text { What does the term 'chemotherapy' mean to you? } \\
\text { Can you describe the thoughts and feelings you experienced when you } \\
\text { were informed that you will be starting treatment with chemotherapy? } \\
\text { What do you think has shaped your thoughts and feelings around } \\
\text { chemotherapy? }\end{array}$ \\
\hline & General attitude towards medicine & What do you think the benefits of chemotherapy will be? \\
\hline & & What are your main concerns about starting chemotherapy? \\
\hline \multirow[t]{2}{*}{ Medicine taking practice } & Accepting medicine & $\begin{array}{l}\text { Were you explained how you shall be receiving the chemotherapy and any } \\
\text { supportive medicines? }\end{array}$ \\
\hline & & $\begin{array}{l}\text { Do you have a network of support (family members, friends, support } \\
\text { groups)? How do they help you? }\end{array}$ \\
\hline \multirow[t]{5}{*}{ Medicine related burden } & Medicine characteristics & $\begin{array}{l}\text { Are there any aspects of chemotherapy such as the pharmaceutical form } \\
\text { (intravenous or oral formulation), colour of size of the tablet, infusion time } \\
\text { that might affect you? }\end{array}$ \\
\hline & Medicine routine & $\begin{array}{l}\text { Do you envisage any problems to follow the treatment schedule as } \\
\text { prescribed? }\end{array}$ \\
\hline & Medicine adverse events & $\begin{array}{l}\text { Do you know when to report side effects to the doctor or other healthcare } \\
\text { professionals? }\end{array}$ \\
\hline & Medicine social burden & Do you feel that chemotherapy will have an impact on your daily life? \\
\hline & $\begin{array}{l}\text { Healthcare-associated medicine } \\
\text { burden }\end{array}$ & What are your experiences with the healthcare system? \\
\hline
\end{tabular}

*Questions pertaining to theme 'Modifying or altering medicine regimen or dose' as part of 'Medicine taking practice' were not included in this interview guide as the patients were interviewed on initiating their treatment with antineoplastic medicines.

PLEM, patients' lived experience with medicines.

\section{Data analysis}

Analysis was carried out using IPA, as outlined by Smith $e t$ $a l .^{20}$ This was conducted using pen and paper according to a systematic and iterative process of coding and recoding. The first step involved two members of the research team $(\mathrm{AB}$ and $\mathrm{PVB})$ independently reading each transcript several times, coding using independent line-by-line analysis and identifying emerging themes for each transcript. Any discrepancies were resolved by discussion, with a third team member (AEW) consulted in instances of non-agreement. The discrepancies were documented to ensure an audit trail and strengthens dependability. The emergent themes were then listed, examined for patterns across all transcripts, grouped into clusters and organised into themes and subthemes. Quotations from the interviews in the Maltese language were translated into the English language by the researcher $(\mathrm{AB})$, followed by a reverse-translation by a second researcher (PVB) fluent in both languages. This ensured the precise contextual meaning of the original quotation.

\section{Patient and public involvement}

Patients and public were not involved in the design and development of this study due to strict time and financial restrictions without funding in this regard. In spite of this, participants consenting to take part were informed of their right to request a copy of the results of this study, thereby forming part of the dissemination strategy.

\section{RESULTS}

\section{Clinical and demographic characteristics}

Sixteen patients participated in the study. Data saturation was reached with the addition of four participants to the initial sample of 12 participants. The participants were mostly females $(n=10,63 \%)$ with a mean age of $62 \pm 10.89$ years (range $38-78$ years). All patients except one received FOLFOX; with 9 patients $(56 \%)$ receiving antineoplastic medicines as adjuvant treatment. Most patients $(\mathrm{n}=9,56 \%)$ were receiving treatment with antineoplastic medicines with curative intent.

\section{Qualitative findings}

Five themes were identified from the analysis, with 16 emerging sub-themes to describe the patients' experience following initiation of treatment with antineoplastic medicines (table 2). Each theme will be described in detail and supported with patient's quotations in separate sections.

\section{Theme 1: beliefs and knowledge on cancer and treatment Beliefs on cancer and treatment}

The beliefs of suffering from treatment effects led patients to experience emotions of 'devastation' [P013] and 'fear of the unknown' [P014] as from the moment of being advised to start treatment with FOLFOX or XELOX. In fact, all patients believed that antineoplastic agents result in alopecia. 
Table 2 Themes and subthemes identified from the interviews

\begin{tabular}{|c|c|}
\hline Themes & Subthemes \\
\hline \multirow[t]{3}{*}{$\begin{array}{l}\text { Beliefs and knowledge on } \\
\text { cancer and treatment }\end{array}$} & $\begin{array}{l}\text { Beliefs on cancer and } \\
\text { treatment }\end{array}$ \\
\hline & $\begin{array}{l}\text { Knowledge on cancer and } \\
\text { treatment }\end{array}$ \\
\hline & $\begin{array}{l}\text { Influences on beliefs and } \\
\text { knowledge }\end{array}$ \\
\hline \multirow[t]{4}{*}{$\begin{array}{l}\text { The healthcare system in } \\
\text { relation to treatment }\end{array}$} & $\begin{array}{l}\text { Exposure to cancer services as } \\
\text { part of healthcare system }\end{array}$ \\
\hline & Communicating information \\
\hline & Interpersonal relationships \\
\hline & $\begin{array}{l}\text { Expectation from healthcare } \\
\text { professionals and healthcare } \\
\text { system }\end{array}$ \\
\hline \multirow[t]{2}{*}{ Medicine-taking practice } & Acceptance of treatment \\
\hline & $\begin{array}{l}\text { Administration of } \\
\text { antineoplastic medicines }\end{array}$ \\
\hline \multirow[t]{5}{*}{ Medicine-related impact } & Physical effect \\
\hline & Psychological effect \\
\hline & Social effect \\
\hline & Economical effect \\
\hline & $\begin{array}{l}\text { Effect on spirituality and } \\
\text { religion }\end{array}$ \\
\hline \multirow[t]{2}{*}{ Personal support structure } & Establishing a support network \\
\hline & Resorting to coping strategies \\
\hline
\end{tabular}

'[...] I thought about my hair...I was really worried that I would experience hair loss and become bald.'. [P009]

The challenging experience that was expected during the treatment journey with antineoplastic medicines was explained by a patient himself with 'climbing up a hill.' [P002] Irrespective of the intent of treatment, all patients were optimistic to achieve complete cure.

'Nothing beats the cure from cancer!...not even the worst adverse effect I may experience.' [P016]

\section{Knowledge on cancer and treatment}

The lack of knowledge of the different treatment modalities for the management of cancer was noted, particularly among patients with adjuvant chemotherapy not being aware that they may need further treatment following surgery.

'The fact that the polyp was surgically removed, I thought that no further treatment was required. Then when I attended the last follow-up, the consultant told me [...] to better receive chemotherapy. Hence the whole treatment plan was never discussed with me.' [P004]
Although patients accepted to start treatment with FOLFOX or XELOX, they were not aware of what it entails in terms of the dosage form and the process of administration of an individualised treatment dose.

'I had no idea...but I was explained about the procedure how to take the medicines mainly today and the first time we met as well. [...] I know that I need to take 2 tablets [Capecitabine] but I do not know exactly the schedule of treatment or how they work.' [P007]

\section{Influences on beliefs and knowledge}

The patient's perception of cancer and its treatment was influenced by the patient's concomitant treatment, chronic conditions and past experiences of family members or friends.

'I remember lately I had a customer who had bone cancer and was receiving chemotherapy. He really changed a lot...from a good looking man to a frail thin man with orange-tinge skin and fine hair.' [P016]

On the other hand, those patients who lacked personal experiences of cancer did not know what to expect. These patients felt the need to speak with other patients with cancer.

'I am the first case of cancer in my family; hence this experience is all new to me. I can only imagine what may happen from what I read online.' [P004]

\section{Theme 2: the healthcare system in relation to treatment Cancer services as part of healthcare system}

Though all patients were naive to treatment with antineoplastic medicines, not all patients had the same exposure of the healthcare system, with each patient following a distinct cancer care pathway.

'Through the screening programme, I was diagnosed with this cancer at its early stage. Hence sparing the need of being given aggressive treatment.' [P004]

The initiation of antineoplastic medicines brought these patients in close contact with cancer-related healthcare services offered within the oncology centre. In between their a first meeting with the oncologist and prior to the initiation of treatment, detailed information about antineoplastic treatment was delivered in a nurse-led educational session to newly diagnosed patients and their significant others. Complementing this service was a 24 hour call out service offered by colorectal nurse navigators. as a contact point for these patients along their cancer journey.

'[...] I attended a meeting of 1 hour and a half on Sunday; this took place not so long ago[...] where these nurses were explaining to us about the treatment in general.' [P015] 


\section{Communicating information}

Although patients commented that the nurse-led information session was informative, they remarked that it was detailed and general to all forms of cancer and treatment. Patients stressed the importance of receiving simple reliable information delivered at the right time in a language that ensures clear understanding without medical jargon. In addition to being highly sensitive to the words used by the healthcare professionals particularly on describing the disease stage, patients observed attentively the attitude and gestures of the healthcare professionals.

'I asked '[...] What are the chance that I live or not live? What are the odds $50 / 50$ or $60 / 40$ ?' He replied that we are not in the business of odds and removed the eye contact. And his body language showed either he was not confident, or it was bad news for me...so it gave me a bad feeling.' [P016]

\section{Interpersonal relationships}

The involvement of healthcare professionals from different specialities working in a multidisciplinary team approach was appreciated by the patients but this could lead to patients' misapprehension of their roles. Being a specialised field, patients were concerned whom to trust and were mainly willing to allow oncology trained healthcare professionals to provide assistance.

'From the hospitality [...], I believe that the nurses here are available for assistance in time of need. They'll offer the necessary care and comfort to make me feel better $[\ldots]$ The expertise of the staff here [oncology centre] puts my mind at rest that I am being treated well' [P008]

\section{Expectations from the healthcare professionals and healthcare system}

Patients expected that healthcare professionals should provide them with quality care while maintaining high professional standards. Being assisted by healthcare professionals wearing a smile made the patients feel comfortable to open up about their situation and stimulate a relationship based on trust.

'I received a phone call from the nurses as I was 20 minutes late for my appointment to receive this treatment $[\ldots]$ they were waiting for me and welcomed me with great love and escorted me to my room.' [P002]

\section{Theme 3: medicine-taking practice \\ Acceptance of treatment}

The decision to accept the treatment relied solely on the oncologist's recommendations. Patients seemed unconcerned about the lack of their involvement in the choice of antineoplastic treatment.

'In view that this treatment was suggested by the oncologist, then it is necessary for me at this stage. This shows that there is a greater potential to get cured.' [P005]

\section{Administration of antineoplastic medicines}

Patients were not expecting that the duration of treatment with antineoplastic medicines will be over a period of 6 months. Despite assuming that antineoplastic medicines are only available as parenteral formulations, the majority of patients remarked that they would still choose this route of administration if given a choice. All female patients remarked that their two-night admission every 2 weeks in the oncology centre for parenteral infusion of FOLFOX was offering them space and time which they can dedicate to their own self and to reflect on their life in a calm environment.

'If I was offered another form of treatment [...], I would not have chosen it. It is better to have healthcare professionals keeping an eye on you [...]. They [Nurses] do not even let you touch the [infusion] bag,...let alone expose all my family to more of these things. Going through this experience is already enough for the family!' [P016]

\section{Theme 4: medicine-related impact}

Physical effect

During their first treatment cycle, the commonly reported physical side effects included altered taste, increased appetite, bleeding gums, diarrhoea and nausea. Some patients also reported feeling physically healthier with less pain at this very early stage of treatment.

'Yesterday, though it was my first day of the first cycle of treatment, I felt less in pain than usual, thank God and today I'm feeling much better. Now we'll see what happens.' [P011]

\section{Psychological effect}

Patients claimed that the diagnosis of cancer and its treatment caused distress. This is because they felt that they were stigmatised by the general public due to the association of cancer and its treatment with death or else life nearing the end. In fact, during the interviews, it was noted that patients avoided using the term 'cancer' but instead were using the terms 'it' or 'the disease' in reference to cancer. They assessed their life priorities, where the focus shifted onto their own self. Additionally, patients were ready to sacrifice their hobbies to get their health back in return.

'I like to work in my small field, but the doctor told me to be careful of the soil and dust... Health must be the first priority! I feel ready to stop any fieldwork activities and make every sacrifice that is deemed necessary.' [P015] 
Social effect

At initiation of treatment with antineoplastic medicines, patients were already experiencing challenges with respect to their social life. As a result of the weakened immune system, all patients were concerned of contracting opportunistic infections. In fact all patients receiving antineoplastic medicines intended to avoid social gatherings. In view of these mitigations, some patients raised concern about risks of feeling solitude.

'I've informed the chaplain that this year I'm refraining from teaching religion to children. He was shocked as I have been doing this for almost 30 years now and I am afraid of spending all my time at home.' [P003]

\section{Economical effect}

The main financial impact was secondary to loss of employment and income. Differing views were noted among patients depending on age. Young patients were worried on how to sustain their loans while older patients were making sure that their partner would have enough income to sustain a living.

'I still have an active loan of my house. The problem is that the doctor told me that I shall spend at least 7 months away from my workplace. [...] My income has been severely affected now that I am on long-term sick leave. I am depending on my siblings for financial assistance to pay the loan.' [P011]

\section{Effect on spirituality and religion}

Patients made strong reference to the religious and spiritual factors at the start of antineoplastic treatment. In the interviews, patients made use of religious themed phrases, such as 'with God's help' [P010] or 'leave it in God's hands.' [P001] [P002] [P015] Faith also featured in the patients' future plans where most of them made a reference to a visit to a religious shrine as an expression of gratitude.

'In reality, I made an agreement with Holy Mary that if I get the result of being cured, the first place to visit will be Lourdes in France.' [P010]

\section{Theme 5: personal support structure}

\section{Establishing support network}

All patients expected to receive all the necessary support from their families to continue living an independent life and only one patient doubted the degree of support that would be provided from her family members. Despite this, patients expressed their concern of being a burden on their family members.

'Because my niece has her own family too...she is not on her own, hence making it more difficult for her to take care of me. [...] Being an elderly lady living on my own, I was considering [...] either to live in a care home or recruiting a full-time carer.' [P005]
Patients also planned to receive support from friends, neighbours, work colleagues, employers and social services. However none of the patients felt the need to attend a support group.

'I do not attend any support group as I do not feel the need. [...] I have friends who offer support and encouragement.' [P012]

\section{Resorting to coping strategies}

Patients were noted to adopt different coping mechanisms to manage their current situation. These included lifestyle change, avoidance, denial and finding a positive meaning in their situation.

'When my friends come over to visit me at home, I instruct them to talk about other subjects [...] to try to forget the current situation.' [P014]

\section{DISCUSSION}

To the best of our knowledge, this is the first qualitative study that explores the patients' lived experience of antineoplastic medicines on initiation of treatment for CRC. This research is important as more than half of the patients diagnosed annually with CRC receive treatment with antineoplastic medicines with the intent to provide either palliation for advanced unresectable disease or curative intent to decrease the risk of recurrence following radical surgery. ${ }^{24}{ }^{25}$ The phenomenological approach was pivotal to bridge the gap in knowledge on how these patients perceive and experience their treatment with antineoplastic medicines at initiation of their treatment journey.

This qualitative study showed that all patients, irrespective to their intent of treatment, believed that the prime goal of treatment with antineoplastic medicines was to achieve cure. Patients had misconceptions on the treatment side effects believing that alopecia is an inevitable consequence of all antineoplastic medicines and showed lack of knowledge on different treatment modalities, despite consenting to treatment and attending to an information session. This is consistent with the quantitative multicentre study of Lorusso $e t a t^{26}$ among Italian patients with malignant haematological or solid cancers, whereby alopecia was reported to be the second most dreaded adverse effect, following nausea and vomiting. The study of Cowley et $a l^{27}$ on women receiving adjuvant chemotherapy for breast cancer, revealed that patients with misconceptions on the rationale of treatment or occurrence of side effects still suffer from anxiety or depression. Hence, adversely affecting their recovery and overall health outcomes. ${ }^{27}$ Therefore, this calls for the need of healthcare professionals to ensure patient education with the aim to clarify misconceptions and provide realistic treatment expectations for patients to be able to make an informed decision prior to treatment's acceptance. 
Fee-Schroeder et $a l^{28}$ assumed that ideally patients' education on treatment should occur prior to initiation of their treatment cycle. However, this contrasts with the findings of our study which showed that at initiation of treatment patients felt overwhelmed with treatment information they were provided. This study identified the need of providing patients with tailored information specific to their planned treatment. This should be supplemented with the sharing of experience of other fellow or previous patients receiving the same treatment to provide them with practical knowledge on coping with cancer and its treatment. The qualitative study by Kaiser $e t a l^{29}$ described that fellow patients will not only serve as a source of information to newly diagnosed patients but will also act as a model to empower them during their treatment journey.

Patients were not concerned regarding their lack of participation in the shared decision making to initiate treatment. These patients relied heavily on the oncologist to make treatment decisions for them; highlighting their trust in the oncologist as being portrayed as the one who has the knowledge, the means and authority to bring about improvement in their health. In fact, patients in our study were not deterred to accept the treatment by the cytotoxic nature of antineoplastic medicines or the associated potential serious life-threatening adverse effects because the perceived threat of death outweighed the perceived benefit of achieving a cure. This riskbenefit assessment by the patients is not necessarily congruent with that of the healthcare professionals as increased patients' survival should be justified with the troublesome adverse effect of treatment with antineoplastic medicines. ${ }^{30-32}$ This contrasts with the findings of the multicentre randomised control trial in Australia and Canada by Leighl et $a l^{33}$ among 207 patients with metastatic CRC whereby $41 \%(\mathrm{n}=85)$ of patients with advanced CRC aspired for shared decision making with oncologist rather than having their oncologist to lead. ${ }^{30}$

With regard to medicine-taking practice, a literature review by Eek $e t a l^{34}$ which evaluated patients' preferences on cancer treatment administration found that oral treatment was preferred to parenteral administration in view of the ease of its administration, perception of increased efficacy and possibly better past experiences. In contrast to our study, patients claimed that even if a choice was given, they would still opt for the parenteral formulation, considering both formulations had the same efficacy. Being in the hospital setting, patients in our study felt a sense of security, assurance of surveillance by experienced healthcare professionals, provision of respite and reduced cytotoxic exposure to their family members. Although not mentioned by the patients, the preference to parental formulation in our study when compared with other research could be attributed to the provision of free healthcare service and shorter travelling distances to hospital locally.

Our study describes that there is a multidimensional impact of treatment with antineoplastic medicines on the patients' lives, affecting them physically, psychologically, socially, economically as well as their spiritual and religious aspects. The latter was the only aspect which exerted a positive impact on the patient's treatment with antineoplastic medicine. Consistent with other research, ${ }^{35}$ religion was noted to instil hope and emotional comfort by offering patients a meaning and purpose in life. The multidimensional impact that antineoplastic medicines have on the patients' life calls for additional research to optimise and tailor support services necessary as from initiation of treatment and along the treatment journey.

The establishment of a personal support network and coping strategies have been shown to be pivotal for patients with CRC even at the beginning of the treatment journey as it has been found that treatment with antineoplastic medicines causes the most significant psychological distress among all treatment modalities. ${ }^{36-38}$ This study complements the findings of Asiedu $e t a l^{99}$ that the provision of support from families decreases anxiety, improves the patient's decision making and survival strategy. In fact patients with CRC who have established social support demonstrated lower stress and higher resilience during treatment resulting in improved survival and QOL. ${ }^{40}$ Hence family members should be made aware of the importance of their role by participating and supporting the patient during the treatment journey. Whilst Kanters $e t a l^{11}$ showed that peer support among patients with CRC favourably affects patients' attitudes and adherence to adjuvant chemotherapy, none of the patients in our study intended to resort to support groups. Although this may be attributed to local culture and strong family bonding, further research is needed to ascertain these attributes. ${ }^{4}$ These findings demonstrate the importance of healthcare professionals to provide a more holistic patient assessment and care taking in consideration the sociocultural aspects of the patient in context. ${ }^{43}$

\section{Future research}

This study provides an insight into the experiences of newly diagnosed patients with CRC on initiation of antineoplastic medicines. Evidence suggests that patients undergo continuous process of reinterpretation of their experiences with medicines throughout their entire treatment journey. ${ }^{17}$ Further longitudinal, qualitative research during and after cessation of the patients' treatment journey is recommended to explore patient's experiences with antineoplastic medicines over time.

\section{Strengths and weaknesses}

To our knowledge, this is the first qualitative study to explore the patients' experience on initiation of treatment with antineoplastic medicines for CRC. The study took place in the only national centre for oncology medicine in Malta, covering a large number of patients locally. The interpretative phenomenological design employed in this study explored the individuals' complex experiences, beliefs and behaviours with antineoplastic medicines. Hence, the study findings can be used to inform delivery of individualised care and support provided to 
these patients. Strategies to promote trustworthiness were employed within this research. These include the provision of quotations from interviews (transferability), research process clearly documented with detailed description of method (dependability), reflexivity (confirmability) and transcription and analysis accuracy check by another researcher (credibility).

This study has some limitations. While the study was carried out in line with research quality markers for robust qualitative IPA studies, ${ }^{19}$ the research team acknowledges that there was a lack of patients and public involvement in the study design. In such intensely emotional experiences, it cannot be assumed that every participant's experience of this phenomenon was captured in its entirety and there may have been limitations of the spoken word. Furthermore the findings reflect the perspective of patients with CRC initiating antineoplastic medicines and although data saturation was achieved, results should be interpreted with caution with regard to generalisability and transferability to other patient groups and settings.

\section{CONCLUSION}

The study findings demonstrate that the experience of patients with CRC at initiation of antineoplastic medicines is complex. It has shown to be highly affected by individual and contextual factors. The study highlighted the lack of patient's knowledge on treatment, the impact experienced on their life and the need to establish a personal support structure to mitigate this impact. Hence patients undergoing antineoplastic treatment need more than fulfilment of medicine administration from hospital. This calls for the need to develop tailored services to address the patients' concern and empower patients to be active participants in their care as from this early stage of treatment.

Acknowledgements The authors would like to thank all the participants in the study for sharing their experiences. Gratitude is also extended to Prof S Cunningham and Ms L MacLeod who formed part of the internal peer review board of the School of Pharmacy and Life Sciences at Robert Gordon University, UK, prior submission for consideration for publication in BMJ Open. Their constructive feedback assisted in improving the quality of this manuscript.

Contributors $A B$ contributed to the conception and design, data collection by conducting the interviews, analysis and interpretation, drafted and reviewed the manuscript. AEW contributed to the conception and design, interpretation and reviewed the manuscript. PVB contributed to the analysis, interpretation and reviewed the manuscript. DS contributed to the conception and design and reviewed the manuscript. All authors have given final approval of the version to be published and agree to be accountable for all aspects of the work in ensuring that questions related to the accuracy or integrity of any part of the work are appropriately investigated and resolved. $A B$ is responsible for the overall content as guarantor.

Funding The research work disclosed in this publication is funded by the Tertiary Education Scholarships Scheme (Malta). The publication of this research work is financed by the Robert Gordon University.

Competing interests None declared.

Patient consent for publication Consent obtained directly from patient(s)

Ethics approval This study was approved by Health Ethics Committee, Ministry for Health, Malta (HEC reference number 12/18) and Ethics Research Committee, The University of Robert Gordon, Aberdeen UK (S131).
Provenance and peer review Not commissioned; externally peer reviewed.

Data availability statement Data are available on reasonable request.

Supplemental material This content has been supplied by the author(s). It has not been vetted by BMJ Publishing Group Limited (BMJ) and may not have been peer-reviewed. Any opinions or recommendations discussed are solely those of the author(s) and are not endorsed by BMJ. BMJ disclaims all liability and responsibility arising from any reliance placed on the content. Where the content includes any translated material, BMJ does not warrant the accuracy and reliability of the translations (including but not limited to local regulations, clinical guidelines, terminology, drug names and drug dosages), and is not responsible for any error and/or omissions arising from translation and adaptation or otherwise.

Open access This is an open access article distributed in accordance with the Creative Commons Attribution Non Commercial (CC BY-NC 4.0) license, which permits others to distribute, remix, adapt, build upon this work non-commercially, and license their derivative works on different terms, provided the original work is properly cited, appropriate credit is given, any changes made indicated, and the use is non-commercial. See: http://creativecommons.org/licenses/by-nc/4.0/.

ORCID iD

Alison Brincat http://orcid.org/0000-0002-5670-2736

\section{REFERENCES}

1 Favoriti P, Carbone G, Greco M, et al. Worldwide burden of colorectal cancer: a review. Updates Surg 2016;68:7-11.

2 Bray F, Ferlay J, Soerjomataram I, et al. Global cancer statistics 2018: GLOBOCAN estimates of incidence and mortality worldwide for 36 cancers in 185 countries. CA Cancer J Clin 2018;68:394-424.

3 Keum N, Giovannucci E. Global burden of colorectal cancer: emerging trends, risk factors and prevention strategies. Nat Rev Gastroenterol Hepatol 2019;16:713-32.

4 Argilés G, Tabernero J, Labianca R, et al. Localised colon cancer: ESMO clinical practice guidelines for diagnosis, treatment and follow-up. Ann Oncol 2020;31:1291-305.

5 Van Cutsem E, Cervantes A, Nordlinger B, et al. Metastatic colorectal cancer: ESMO clinical practice guidelines for diagnosis, treatment and follow-up. Ann Oncol 2014;25 Suppl 3:iii1-9.

6 Van Cutsem E, Cervantes A, Adam R, et al. ESMO consensus guidelines for the management of patients with metastatic colorectal cancer. Ann Oncol 2016;27:1386-422.

7 Buetto LS, Zago MMF. Meanings of quality of life held by patients with colorectal cancer in the context of chemotherapy. Rev Lat Am Enfermagem 2015;23:427-34.

8 Glimelius B, Cavalli-Björkman N. Metastatic colorectal cancer: current treatment and future options for improved survival. Medical approach--present status. Scand J Gastroenterol 2012;47:296-314.

9 Zhang M, Peng L, Liu W, et al. Physical and psychological predictors of quality of life in Chinese colorectal cancer patients during chemotherapy. Cancer Nurs 2015;38:312-21.

10 Guren MG. The global challenge of colorectal cancer. Lancet Gastroenterol Hepatol 2019;4:894-5.

11 GBD 2017 Colorectal Cancer Collaborators. The global, regional, and national burden of colorectal cancer and its attributable risk factors in 195 countries and territories, 1990-2017: a systematic analysis for the global burden of disease study 2017. Lancet Gastroenterol Hepatol 2019;4:913-33.

12 Zhang M-fen, Zheng M-chun, Liu W-yan, et al. The influence of demographics, psychological factors and self-efficacy on symptom distress in colorectal cancer patients undergoing post-surgical adjuvant chemotherapy. Eur J Oncol Nurs 2015;19:89-96.

13 Ito N, Ishiguro M, Uno M, et al. Prospective longitudinal evaluation of quality of life in patients with permanent colostomy after curative resection for rectal cancer: a preliminary study. J Wound Ostomy Continence Nurs 2012;39:172-7.

14 Jones SMW, Ziebell R, Walker R, et al. Association of worry about cancer to benefit finding and functioning in long-term cancer survivors. Support Care Cancer 2017;25:1417-22.

15 Clark CJ, Fino NF, Liang JH, et al. Depressive symptoms in older long-term colorectal cancer survivors: a population-based analysis using the SEER-Medicare healthcare outcomes survey. Support Care Cancer 2016;24:3907-14

16 Mohammed MA, Moles RJ, Chen TF. Medication-Related burden and patients' lived experience with medicine: a systematic review and metasynthesis of qualitative studies. BMJ Open 2016;6:e010035-51.

17 Brincat A, Bonanno PV, Stewart D, et al. Patients' lived experiences with antineoplastic medicines for the management of malignant 
solid tumours: a systematic review. Res Social Adm Pharm 2020;16:450-63.

18 O'Brien BC, Harris IB, Beckman TJ, et al. Standards for reporting qualitative research: a synthesis of recommendations. Acad Med 2014;89:1245-51.

19 Lincoln YS, Guba EG, Pilotta JJ. Naturalistic inquiry. Newbury Park, CA: Sage Publications, 1985: 9. 438-9.

20 Smith JA, Flowers P, Larkin M. Interpretative Phenomenological Analysis: Theory, Method and Research. UK: Sage Publications, 2012.

21 Senior V, Smith JA, Michie S, et al. Making sense of risk: an interpretative phenomenological analysis of vulnerability to heart disease. J Health Psychol 2002;7:157-68.

22 InvestEU. Improving treatment for cancer patients at the mater dei Hospital. Available: https://europa.eu/investeu/projects/improvingtreatment-cancer-patients-mater-dei-hospital_en [Accessed 17 Oct 2020].

23 Francis $\mathrm{JJ}$, Johnston $\mathrm{M}$, Robertson $\mathrm{C}$, et al. What is an adequate sample size? Operationalising data saturation for theory-based interview studies. Psychol Health 2010;25:1229-45.

24 Aschele C, Bergamo F, Lonardi S. Chemotherapy for operable and advanced colorectal cancer. Cancer Treat Rev 2009;35:509-16.

25 Weeks JC, Catalano PJ, Cronin A, et al. Patients' expectations about effects of chemotherapy for advanced cancer. N Engl J Med 2012;367:1616-25.

26 Lorusso D, Bria E, Costantini A, et al. Patients' perception of chemotherapy side effects: Expectations, doctor-patient communication and impact on quality of life - An Italian survey. Eur $J$ Cancer Care 2017;26:e12618.

27 Cowley L, Heyman B, Stanton M, et al. How women receiving adjuvant chemotherapy for breast cancer cope with their treatment: a risk management perspective. $J$ Adv Nurs 2000;31:314-21.

28 Fee-Schroeder K, Howell L, Kokal J, et al. Empowering individuals to self-manage chemotherapy side effects. Clin J Oncol Nurs 2013;17:369-71.

29 Kaiser M, Adami S, Lucius-Hoene G, et al. Learning-by-doing: the importance of experiential knowledge sharing for meeting the information needs of people with colorectal cancer in Germany-a qualitative study. BMJ Open 2021;11:e038460.

30 Buiting HM, Rurup ML, Wijsbek $\mathrm{H}$, et al. Understanding provision of chemotherapy to patients with end stage cancer: qualitative interview study. BMJ Support Palliat Care 2011;1:33-41.
31 Wakiuchi J, Marcon SS, Oliveira DCde, et al. Chemotherapy under the perspective of the person with cancer: a structural analysis. Texto contexto - enferm. 2019;28:e20180025

32 Taylor C. Patients' experiences of 'feeling on their own' following a diagnosis of colorectal cancer: a phenomenological approach. Int $J$ Nurs Stud 2001;38:651-61.

33 Leighl NB, Shepherd HL, Butow PN, et al. Supporting treatment decision making in advanced cancer: a randomized trial of a decision aid for patients with advanced colorectal cancer considering chemotherapy. J Clin Oncol 2011;29:2077-84.

34 Eek D, Krohe M, Mazar I, et al. Patient-Reported preferences for oral versus intravenous administration for the treatment of cancer: a review of the literature. Patient Prefer Adherence 2016;10:1609-21.

35 Nejat N, Whitehead L, Crowe M. The use of spirituality and religiosity in coping with colorectal cancer. Contemp Nurse 2017;53:48-59.

36 Herschbach P, Book K, Brandl T, et al. Psychological distress in cancer patients assessed with an expert rating scale. $\mathrm{Br} J$ Cancer 2008;99:37-43.

37 Maguire R, Hanly P, Hyland P, et al. Understanding burden in caregivers of colorectal cancer survivors: what role do patient and caregiver factors play? Eur J Cancer Care 2018;27:e12527.

38 Céilleachair Alan Ó, Costello L, Finn C, et al. Inter-Relationships between the economic and emotional consequences of colorectal cancer for patients and their families: a qualitative study. BMC Gastroenterol 2012;12:230X-12- 62.

39 Asiedu GB, Eustace RW, Eton DT, et al. Coping with colorectal cancer: a qualitative exploration with patients and their family members. Fam Pract 2014;31:598-606.

40 Miles A, McClements PL, Steele RJC, et al. Perceived diagnostic delay and cancer-related distress: a cross-sectional study of patients with colorectal cancer. Psychooncology 2017;26:e36

41 Kanters AE, Morris AM, Abrahamse PH, et al. The effect of peer support on colorectal cancer patients' adherence to Guideline-Concordant multidisciplinary care. Dis Colon Rectum 2018;61:817-23.

42 Calderón C, Jimenez-Fonseca P, Jara C, et al. Comparison of coping, psychological distress, and level of functioning in patients with gastric and colorectal cancer before adjuvant chemotherapy. $J$ Pain Symptom Manage 2018;56:399-405.

43 Sari DK, Dewi R, Daulay W. Association between family support, coping strategies and anxiety in cancer patients undergoing chemotherapy at General Hospital in Medan, North Sumatera, Indonesia. Asian Pac J Cancer Prev 2019;20:3015-9. 